\title{
Biogenic silver nanoparticles on carbonaceous material from sewage sludge for degradation of methylene blue in aqueous solution
}

\author{
A.-R. Vilchis-Nestor $\cdot$ J. Trujillo-Reyes $\cdot$ J. A. Colín-Molina $\cdot$ \\ V. Sánchez-Mendieta $\cdot$ M. Avalos-Borja
}

Received: 15 October 2012/Revised: 11 January 2013/Accepted: 23 April 2013/Published online: 17 May 2013

(C) Islamic Azad University (IAU) 2013

\begin{abstract}
Silver nanoparticles (Ag NPs) were synthesized in situ, using a one-step green methodology with Camellia sinensis (green tea) aqueous extract as reducing agent, and supported on a carbonaceous material (Ag-CM), originated from the pyrolysis of sewage sludge. UV-Vis spectroscopy, X-ray diffraction, scanning electron microscopy, transmission electron microscopy and Brunauer-EmmetTeller were used to characterize the nanocomposite. Ag$\mathrm{CM}$ composite exhibited very good catalytic activity in the degradation process of methylene blue (MB) dye in aqueous solution without using sunlight or UV radiation. Batch kinetic and isothermal experiments, using $30 \mathrm{mg} / \mathrm{L} \mathrm{MB}$ solution, showed that Ag-CM composite removed near to $91 \%$ of $\mathrm{MB}$ in $9 \mathrm{~h}$, whereas the carbonaceous material alone removed only $60 \%$ in $30 \mathrm{~h}$. Experimental data were
\end{abstract}

Miguel Avalos-Borja is on leave at IPICyT, Division de Materiales Avanzados,San Luis Potosi, S.L.P., 78216, Mexico. e-mail: miguel.avalos@ipicyt.edu.mx

\section{A.-R. Vilchis-Nestor}

Centro Conjunto de Investigación en Química Sustentable,

UAEM-UNAM, Carretera Toluca-Atlacomulco Km 14.5,

San Cayetano, Piedras Blancas, 50200 Toluca,

Estado de México, Mexico

A.-R. Vilchis-Nestor · M. Avalos-Borja

Centro de Nanociencia y Nanotecnología,

Universidad Nacional Autónoma de México,

Km 107 Carretera Tijuana-Ensenada, AP. 2681,

22800 Ensenada, BC, Mexico

J. Trujillo-Reyes $(\bowtie) \cdot$ J. A. Colín-Molina ·

V. Sánchez-Mendieta

Facultad de Química, Universidad Autónoma del Estado de

México, Paseo Colón y Paseo Tollocan s/n.,

50120 Toluca, Mexico

e-mail: jtrujillor@uaemex.mx adjusted to different kinetic and isotherms models, where both materials fit the second-order and Langmuir-Freundlich models, respectively; therefore, a chemisorption mechanism probably occurs in these heterogeneous materials.

Keywords Silver nanoparticles - Bioreduction · Sewage sludge $\cdot$ Biocomposite $\cdot$ Removal $\cdot$ Dyestuff

\section{Introduction}

Cross-disciplinary nanoscience research, involving chemists, physicists, biologists and engineers, is concerned about the need for developing environmentally friendly and sustainable methods for the synthesis of nanomaterials (Gericke and Pinches 2006). There is a current drive to integrate all the green chemistry approaches to design environmentally benign materials and processes.

The physicochemical and optoelectronic properties of metallic nanoparticles are strongly dependent on the size and size distribution; thus, numerous methodologies were formulated in the past to synthesize noble metal nanoparticles of particular shape and size depending on specific requirements. Nevertheless, the routine physicochemical techniques for nanoparticle production, such as photochemical reduction (Eustis et al. 2005), laser ablation (Mafune et al. 2002), electrochemistry (Rodríguez-Sánchez et al. 2000), lithography (Zhang and Wang 2008) or highenergy irradiation (Treguer et al. 1998), either remain expensive or employ hazardous substances, such as organic solvents and toxic-reducing agents like sodium borohydride and $N, N$-dimethylformamide. In addition, due to the high surface energy of the nanoparticles, these tend to form aggregates; therefore, surface passivation and capping 
reagents are frequently added to the reaction systems to avoid coalescence.

Recently, the biosynthesis of nanoparticles, as an emerging highlight of the intersection between nanotechnology and biotechnology, has received increasing attention due to an ever-growing need to develop eco-friendly nanostructure synthesis procedures, with a reasonable control over the size and morphology (Anastas and Kirchhoff 2002; Mohanpuria et al. 2008). The biosynthetic methods employ micro-organisms (Bhattacharya and Gupta 2005) such as bacteria (He et al. 2007) and fungus (Xie et al. 2007). The use of the plants can also be suitably scaled up for large-scale synthesis of metallic nanoparticles, employing either living-inside route (Bali et al. 2006) or via plant extracts (Kumar and Yadav 2008). Biological synthetic procedures for nanoparticles would be more useful if nanoparticles were produced extracellularly using plant extracts and in a controlled manner according to their size, dispersity and shape. Thus, this biosynthetic procedure has emerged as a simple, low-cost and ecofriendly approach to synthesize silver nanoparticles. In this sense, the bioreduction method, using plant extracts, has been developed during the last years for the fabrication of noble metal nanoparticles in suspension solution. We found (Vilchis-Nestor et al. 2008) that a simple and efficient green nanochemistry approach is enough to prepare successfully gold and silver nanoparticles with a homogeneous size distribution in aqueous solution at room conditions, using a renewable and low-cost biological reducing agent, Camellia sinensis plant extract, avoiding, thus, the presence of hazardous and toxic solvents or residues.

Wastewater effluents from some industries, such as textile, leather, paper and plastics, contain several kinds of synthetic dye residues. A very small amount of dye in water is highly visible and can be toxic to life and human beings. Hence, the removal of colour from waste effluents becomes of fundamental importance to the environment, but it requires special and advanced treatments. There are several ways in which colourants cause problems in water, depending on exposure time and dye concentration (Slokar and Le Marechal 1998; Vautier et al. 2001; Mittal et al. 2006). Powder activated carbon has been the most widely used adsorbent for removing organic compounds, including textile dye residues, from wastewater (Kargi and Ozmihci 2004a, b; Kunwar et al. 2003; Hsieh and Teng 2000). Also, the problem of sewage sludge disposal is proving to be one of the most complex environmental problems nowadays. The amount of sewage sludge generated by wastewater treatment plants has been increasing at a rapid pace in recent years and has drawn serious attention from the society (Smith et al. 2009). The decline or loss of the traditional disposal routes for sewage sludge has created a high demand for more cost-effective and environmentally benign alternatives. One potential option for sludge's added value is its conversion into adsorbents, especially activated carbon (Smith et al. 2009; Rozada et al. 2003; Serpil and Fikret 2006; Wang et al. 2008; Trujillo-Reyes et al. 2010). Hence, using metal nanoparticles in combination with low-cost adsorbent materials has attracted much attention over the last decade (Bokare et al. 2007; Trujillo-Reyes et al. 2010, 2012a, b) due to the improved catalytic properties of these types of nanocomposites.

Methylene blue IUPAC name is 3,7-bis (dimethylamino)-phenothiazin-5-ium chloride, is an aromatic heterocyclic compound and an antioxidant that can be easily reduced in the presence of organic electron donators. Because of its chemical structure, MB can self-oxidize 'donating' electrons to other compounds. Those properties had allowed this dye to be the perfect drug to treat the metahaemoglobinaemia, a medical condition characterized for the presence of high concentrations of oxidized haemoglobin in blood. It is also used as a dye to paint certain parts of the body before or during a surgery, as an antiseptic and intern healing. Also, this dye is used in the bacterial staining for microscopic observation (Ma et al. 2004).

Most of the previous works dealing with removing of organic dyes from aqueous solutions or wastewater using $\mathrm{Ag}$ nanoparticles make use of the photocatalysis process to achieve this purpose (Wu et al. 2010; Wang et al. 2012; Rodríguez-González et al. 2012).

Herein, a novel and simple green synthetic methodology for silver nanoparticle preparation and their support on a carbonaceous material (CM) obtained from the pyrolysis of sewage sludge is described. This method involves the in situ reduction of aqueous $\operatorname{Ag}(\mathrm{I})$ ions employing $C$. sinensis (green tea) aqueous extract as a reducing agent in the presence of the supported material. The nanostructured composite material (Ag-CM) showed very good performance for removing methylene blue from aqueous solution.

\section{Materials and methods}

Methylene blue (MB) dye

Methylene blue $\left(\mathrm{C}_{16} \mathrm{H}_{18} \mathrm{ClN}_{3} \mathrm{~S}\right)$ was obtained from Sigma Aldrich $(95 \%)$. MB is a synthetic, cationic, thiazine dye. The general characteristics of this dye are as follows: molar mass $319.87 \mathrm{~g} / \mathrm{mol}$ and maximum light absorption at $\lambda_{\max }=661 \mathrm{~nm}$. 
Carbonaceous material from sewage sludge

Sludge was obtained from RECICLAGUA, a wastewater treatment plant in Lerma, Estado de México, México. The pyrolysis of sewage sludge was carried out at $500{ }^{\circ} \mathrm{C}$ for $60 \mathrm{~min}$. The complete methodology has been described elsewhere (Colín-Cruz et al. 2001). Carbonaceous material was washed with distilled water and dried at $100{ }^{\circ} \mathrm{C}$ for 3 days, crushed and sieved $(20$ mesh $=0.84 \mathrm{~mm})$.

Preparation of carbonaceous material-silver nanoparticles composite

Ten millilitres of $10^{-3} \mathrm{M} \mathrm{AgNO}_{3}$ aqueous solution and $10 \mathrm{~mL}$ of deionized water were added to $2 \mathrm{~g}$ of carbonaceous material in constant stirring for $1 \mathrm{~h}$. Then, $4 \mathrm{~mL}$ of C. sinensis (green tea) aqueous extract was poured into the reaction mixture, with constant stirring for $12 \mathrm{~h}$. The solid material was filtered and dried for $24 \mathrm{~h}$ at $110{ }^{\circ} \mathrm{C}$.

A second experiment to obtain the metallic nanoparticles was carried out under identical reaction conditions; however, prior to drying, the reaction mixture was filtered and the solution was collected in order to perform UV-Vis spectra of silver nanoparticles at different times.

\section{Characterization}

The UV-visible spectra were recorded on a Varian CARY 300 UV-visible spectrophotometer using quartz cuvettes.

Transmission electron microscopy (TEM) and selected area electron diffraction (SAED) were carried out using a JEOL 2010 microscope operating at $200 \mathrm{kV}$ accelerating voltage. The composite was dispersed in 2-propanol at room temperature. A drop of the suspension was placed on a carbon-coated $\mathrm{Cu}$ grid. At least 10 representative images were taken for each sample. In order to obtain statistically consistent information on the particle size distribution, the length of circa 300 particles was measured.

Scanning electron microscope (SEM) observations were carried out on a JEOL 5300. The composite was attached to the sample stub using conductive double-stick tape without coating.

BET surface area was determined by standard multipoint techniques of nitrogen adsorption, using a Micromeritics Gemini 2360 instrument.

\section{Sorption kinetics}

Kinetic removal of MB dye by carbonaceous material-silver nanoparticles composite (Ag-CM) and by $\mathrm{CM}$ alone, from sewage sludge, was as follows: $10 \mathrm{~mL}$ of $\mathrm{MB}$ solution of $30 \mathrm{mg} / \mathrm{L}$ which was added to $10 \mathrm{mg}$ of each adsorbent material. Each material and the solution entered in contact with constant stirring using assay tubes which were put inside plastic containers. Experiments were carried out by batch technique without any illumination in order to avoid photocatalysis. Each plastic container was shaken using a platform shaker at $25 \mathrm{rpm}$ for different times $(0.016,0.083$, $0.25,0.5,1,2,3,5,19$ and $43 \mathrm{~h}$ ) at room temperature and $\mathrm{pH}$ data were monitored before and after the experiments; after that the filtration was performed. MB dye concentration in liquid phase was determined using an UV/visible spectrophotometer Perkin-Elmer Lambda 25 at $\lambda=$ $661 \mathrm{~nm}$. All experiments were done in duplicate.

\section{Sorption isotherms}

Isotherms were carried out using $10 \mathrm{~mL}$ of $\mathrm{MB}$ dye solution at different concentrations 5, 10, 20, 30, 50, 100, 200, 300 and $500 \mathrm{mg} / \mathrm{L}$ which were added to 1 and $10 \mathrm{mg}$ of each adsorbent material using assay tubes which were put inside plastic containers. Experiments were carried out by batch technique without any illumination in order to avoid photocatalysis. Each plastic container was shaken using a platform shaker at $25 \mathrm{rpm}$ for $9 \mathrm{~h}$ for the composite $\mathrm{Ag}$ $\mathrm{CM}$, and $30 \mathrm{~h}$ for the $\mathrm{CM}$ from sewage sludge, respectively, monitoring $\mathrm{pH}$ data before and after the experiments at room temperature. All experiments were done in duplicate. The samples were filtrated and dye concentrations were determined in the liquid phase as described above.

\section{Results and discussion}

\section{Ag-CM composite}

Carbonaceous material was obtained successfully from the pyrolysis of sewage sludge at $500{ }^{\circ} \mathrm{C}$ for $60 \mathrm{~min}$. The Ag$\mathrm{CM}$ composite was prepared efficiently by impregnation of $\operatorname{Ag}(\mathrm{I})$ ions on carbonaceous material in aqueous media; followed by a bioreduction process at room conditions, assisted by $C$. sinensis extract. The characteristic yellowish colour of the solution containing silver nanoparticles provides a convenient visual signature to indicate their formation (inset Fig. 1a). The nominal Ag loading in Ag-CM composite was $0.05 \mathrm{wt} \%$.

\section{Characterization}

Figure 1a shows the UV-visible spectra of the silver nanoparticles obtained after $24 \mathrm{~h}$ of reaction. It is observed that as the reaction progresses, the absorbance intensity peak at $423 \mathrm{~nm}$ increases monotonically as a function of time, without any shift in the peak wavelength. The spectra were measured from the solutions collected after the filtration of the reaction mixture. Figure $1 \mathrm{~b}$ exhibits a plot of 

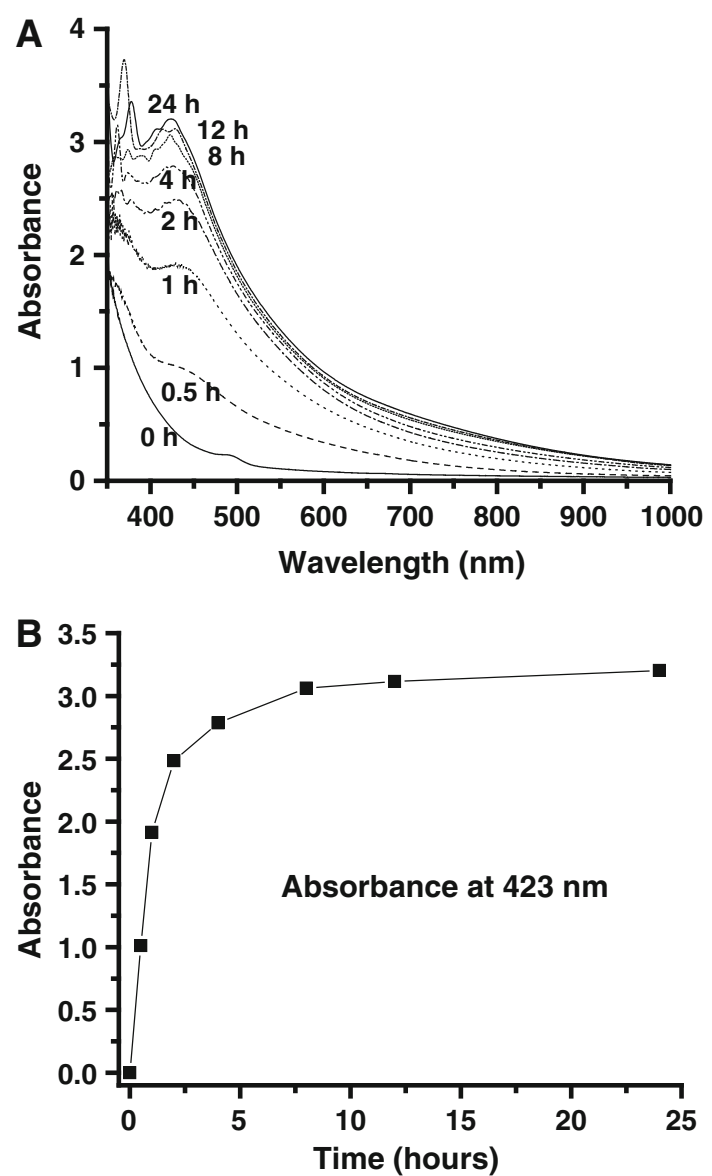

Fig. 1 a UV-Vis spectra recorded as a function of reaction time. The time reaction is indicated next to the corresponding curve. b Plot of the intensity of plasmon resonance at $423 \mathrm{~nm}$ against the reaction time

the plasmon intensity at $423 \mathrm{~nm}$ against reaction time. After $8 \mathrm{~h}$ of reaction time, the plasmon intensities become closer to each other, meaning completion of the reaction. As can be observed in Fig. 1a, a band bellow $400 \mathrm{~nm}$ appears after $2 \mathrm{~h}$ of reaction. This new band around $375 \mathrm{~nm}$ can be attributed to shape modifications of silver nanoparticles. It is well established (Noguez 2007) that shape of metal nanoparticles strongly affects their surface plasmon resonance. Also, it is well known that $C$. sinensis contains polyphenols; a green tea aqueous extract contains $59.8 \mathrm{mg}$ $\mathrm{CAE} / \mathrm{g}$ of phenolic compounds $(\mathrm{CAE}=$ chlorogenic acid equivalents in milligrams per gram of dry material) and terpenoids, among the major biocomponents with antioxidant activity. These types of compounds contribute to the metal ion reduction processes and can also control the size and the stability of the nanostructures formed (VilchisNestor et al. 2008). In the case of silver, there are indications that the presence of polyhedral shapes can generate absorption bands bellow $400 \mathrm{~nm}$ (Kelly et al. 2003). Figures 2 and 3 show TEM micrographs of silver nanoparticles which confirm the presence of non-spherical particles.
Figure 2a shows typical TEM micrographs of the $\mathrm{Ag}$ nanoparticles obtained after $24 \mathrm{~h}$ of reduction using $C$. sinensis aqueous extract. It can be observed that the overall morphology of the sample is composed mainly of isotropic silver nanoparticles. Figure $2 b$ shows the SAED pattern, which reveals that the diffraction rings can be indexed as (111), (200), (220) and (311) reflections, corresponding to an FCC silver structure.

A lower-magnification TEM micrograph and a histogram of the size distribution of silver nanoparticles are shown in Fig. 3a, b, respectively. TEM analysis reveals that nanostructures are predominately ellipsoidal, and polyhedral but also a few spherical nanoparticles are formed (Fig. 3a). Thus, size distribution of silver nanoparticles is not narrow, and the average size was estimated to be $26 \mathrm{~nm}$.

SEM micrographs of $\mathrm{Ag}-\mathrm{CM}$ composite are shown in Fig. $4 \mathrm{a}, \mathrm{b}$ and were recorded with secondary electron detector and backscattered electron detector in composition mode, respectively. From the SEM image in Fig. 4a, a porous material with heterogeneous surface morphology can be observed. After MB removal, the composite keeps its previous typical morphology (Fig. 4b), but with apparently less compact granules, having these smaller sizes. According to Smith et al. (2009), the main constituents of sewage sludge are proteins, fats (soap, oil and grease), silica, nitrogen, phosphoric acid, iron, calcium oxide, alumina, magnesium oxide and potash. Heavy metals and a wide variety of minerals are also present. Similar results were obtained by elemental analysis before and after dye removal for the $\mathrm{Ag}-\mathrm{CM}$ composite, as shown in Table 1. As expected, carbon is the principal element counting for $50 \%$ of Ag-CM composite, in addition to nitrogen, oxygen, calcium, iron, phosphorus and silicon, among other elements. Differences in chemical composition of carbon material samples obtained from sewage sludge are common, due mainly to the different kinds of pollutants present in the diverse sources of treated water. In addition, it is important to point out that EDS is a punctual and a semi-quantitative technique; therefore, it is very difficult to reproduce results. Nevertheless, it gives a good idea of the almost unchanged conditions in the carbonaceous material before and after contact with $\mathrm{MB}$ aqueous solution.

The BET surface areas for $\mathrm{Ag}-\mathrm{CM}$ composite and $\mathrm{CM}$ were 18 and $23 \mathrm{~m}^{2} / \mathrm{g}$, respectively. This result is probably due to $\mathrm{Ag}$ nanoparticles occupying the pores or active sites in the CM, resulting in a lower surface area for the composite. Although specific surface area of both materials is similar, the results described in the following section show that Ag-CM composite has removed MB more efficiently than the carbonaceous material. Thus, sorption capacity increases when Ag nanoparticles are supported on the carbonaceous material, which can be mainly attributed to the capacity of $\mathrm{Ag}$ particles to catalyse the reduction reaction process occurring during degradation of the MB dye. 
Fig. 2 a Representative TEM images of Ag NPs synthesized in aqueous solution after $24 \mathrm{~h}$ of reaction. b Electron diffraction pattern of the Ag NPs
Fig. 3 a Transmission electron micrograph of Ag NPs formed after $24 \mathrm{~h}$ of bioreduction. b Histogram of size distribution of the Ag NPs synthesized by the experiment using $4 \mathrm{~mL}$ of C. sinensis aqueous extract as reducing agent. The average size distribution is $26.3 \mathrm{~nm}$
Fig. 4 Representative SEM micrographs of Ag-CM composites in (a) secondary electrons mode

(b) backscattered electrons mode
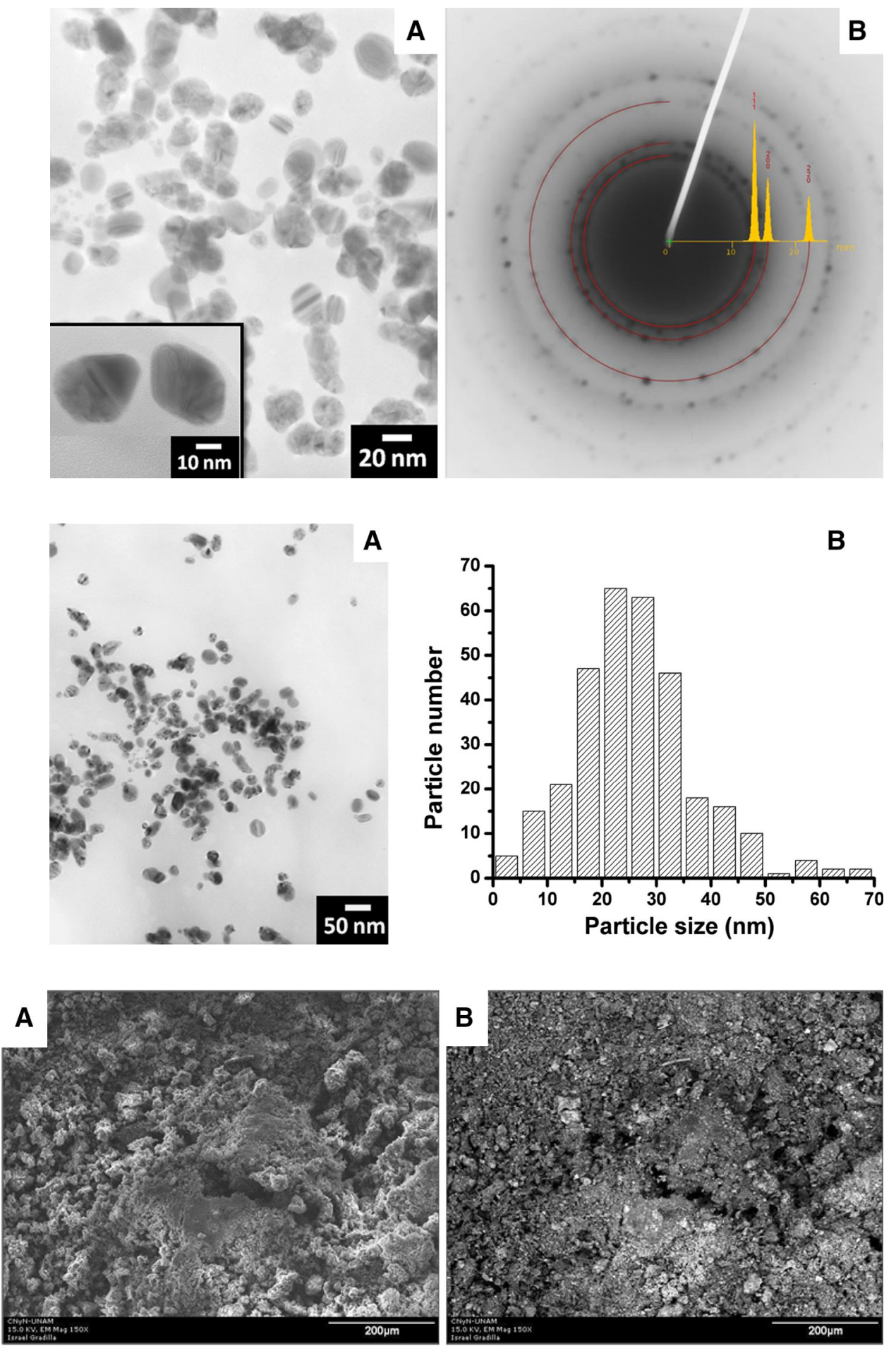

\section{Sorption kinetics}

Sorption studies were performed in duplicate by batch technique to obtain equilibrium data.

Figure 5a shows the kinetic sorption behaviour of the MB dye by Ag-CM composite and CM from pyrolysis of sewage sludge. It can be observed that the CM removes about $60 \%$ of the $\mathrm{MB}$ in an equilibrium time of approximately $30 \mathrm{~h}$.
However, when silver nanoparticles were added to the carbonaceous material, the removal capacity of MB increases. The equilibrium was reached in $9 \mathrm{~h}$ and eliminating near to $91 \%$ of $\mathrm{MB}$ dye. $\mathrm{pH}$ data were monitored before experiments with values of 5.2 and 6.1 for $\mathrm{Ag}-\mathrm{CM}$ and CM, respectively, and after the experiments were 6.95 and 6.75 for Ag-CM composite and CM, respectively. It seems that the combination of sewage sludge and Ag NPs can increase 
the adsorption properties of the composite in the removal of methylene blue from aqueous solution. This can be a promising material in the elimination of some other dyestuffs or organic compounds in real wastewater.

At the equilibrium, the amount of MB dye onto the corresponding material, $q_{\mathrm{e}}(\mathrm{mg} / \mathrm{g})$, was found by a mass balance relationship:

$q_{\mathrm{e}}=\left(C_{\mathrm{o}}-C_{\mathrm{e}}\right) V / W$

where $C_{\mathrm{o}}(\mathrm{mg} / \mathrm{L})$ and $C_{\mathrm{e}}(\mathrm{mg} / \mathrm{L})$ are the initial and the equilibrium liquid-phase concentration of metal, respectively, $V(\mathrm{~L})$ the volume of the solution and $W(\mathrm{~g})$ the weight of the corresponding material, Ag-CM and CM.

Numerous kinetic models and mathematical correlations have been derived to determine the various sorption rate parameters. Experimental data were fitted to different kinetic models like pseudo-first-order or Lagergren model and second-order or Elovich model using the Statistica 6.0 software.

Table 1 EDS analysis before and after dye elimination by Ag-CM composite

\begin{tabular}{llc}
\hline Element & \multicolumn{2}{l}{ Weight percentage } \\
\cline { 2 - 3 } & Ag-CM & After sorption \\
\cline { 2 - 3 } & Before sorption & $52.0 \pm 0.71$ \\
$\mathrm{C}$ & $57.8 \pm 0.65$ & $24.0 \pm 4.92$ \\
$\mathrm{O}$ & $9.6 \pm 0.72$ & $2.3 \pm 1.43$ \\
$\mathrm{P}$ & $1.1 \pm 0.24$ & $9.3 \pm 0.55$ \\
$\mathrm{Si}$ & $7.8 \pm 0.87$ & $0.5 \pm 0.03$ \\
$\mathrm{Na}$ & $0.5 \pm 0.19$ & $0.4 \pm 0.10$ \\
$\mathrm{Mg}$ & $0.2 \pm 0.01$ & $3.2 \pm 1.36$ \\
$\mathrm{Al}$ & $1.6 \pm 0.17$ & $0.8 \pm 0.21$ \\
$\mathrm{~S}$ & $0.9 \pm 0.02$ & $0.09 \pm 0.01$ \\
$\mathrm{Cl}$ & $0.6 \pm 0.47$ & $0.5 \pm 0.03$ \\
$\mathrm{~K}$ & $0.5 \pm 0.14$ & $2.7 \pm 1.18$ \\
$\mathrm{Ca}$ & $1.8 \pm 0.68$ & $0.4 \pm 0.001$ \\
$\mathrm{Ti}$ & $0.4 \pm 0.03$ & $0.3 \pm 0.16$ \\
$\mathrm{Cr}$ & $0.3 \pm 0.01$ & $2.0 \pm 0.91$ \\
$\mathrm{Fe}$ & $1.4 \pm 0.07$ &
\end{tabular}

Pseudo-first-order model (Lagergren)

This model is used for homogeneous materials and physical sorption where sorption velocity is proportional to the solute concentration. If the adsorption process follows a pseudo-first-order kinetics, the sorption constants are obtained by the following equation.

$q_{t}=q_{\mathrm{e}}\left(1-e^{-K_{\mathrm{L}} t}\right)$

This model is based on the evolution of the charge with respect to the time, where $q_{\mathrm{e}}$ and $q_{t}$ denote the amounts adsorbed in the equilibrium and at time $t$, respectively, in $\mathrm{mg} / \mathrm{g}$, and $K_{\mathrm{L}}$ is the Lagergren adsorption constant $\left(\mathrm{h}^{-1}\right)$.

Table 2 shows the kinetic parameters of dye sorption by Ag-CM composite and CM. It can be observed that the amount of dye removed in the equilibrium $\left(q_{\mathrm{e}}\right)$ is 23.34 and $16.19 \mathrm{mg} / \mathrm{g}$ for $\mathrm{Ag}-\mathrm{CM}$ composite and CM, respectively. Both values are lower than those obtained experimentally. The Lagergren constant is similar for both materials; it means that the removal velocity is almost the same. However, this model is not the best to fit the experimental data of the Ag-CM composite and CM because of the lower correlation coefficient values.

\section{Second-order model (Elovich)}

Elovich's equation is another rate equation based on the adsorption capacity. If the adsorption process follows a second-order model, the sorption constants can be obtained by the following equation:

$q_{t}=\left(\frac{1}{b}\right) \ln (1+(a b t))$

where $a$ and $b$ are the sorption and desorption constants of the dye, respectively. This Elovich's equation is commonly used to determine the kinetics of chemisorption onto heterogeneous solids (Yuh-Shan 2006).

Table 2 also shows the kinetic parameters of the MB sorption by the two materials for the Elovich model. The
Fig. 5 a Kinetic studies of AgCM composite and CM. b Elovich kinetic model for adsorption of MB by Ag-CM composite and $\mathrm{CM}$
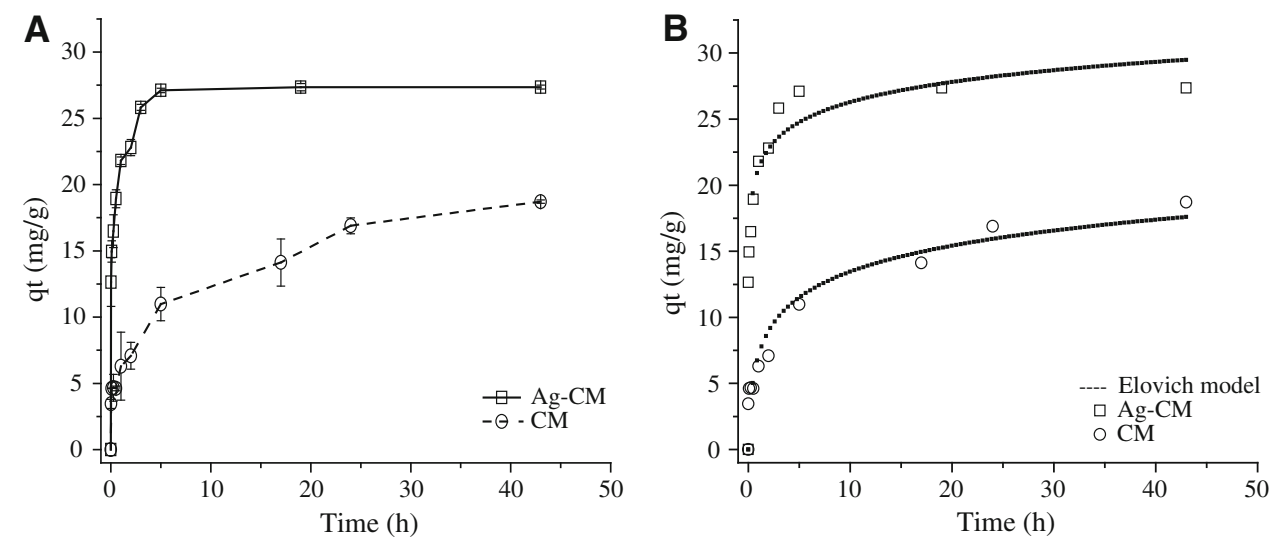
Table 2 Kinetic parameters of the dye sorption by Ag-CM composite and $\mathrm{CM}$

\begin{tabular}{|c|c|c|c|c|c|c|}
\hline \multirow[t]{3}{*}{ Material } & \multicolumn{6}{|c|}{ Kinetic models } \\
\hline & \multicolumn{3}{|l|}{ Lagergren } & \multicolumn{3}{|l|}{ Elovich } \\
\hline & $q_{\mathrm{e}}(\mathrm{mg} / \mathrm{g})$ & $K_{\mathrm{L}}\left(\mathrm{h}^{-1}\right)$ & $r^{2}$ & $a(\mathrm{mg} / \mathrm{g})$ & $b(\mathrm{mg} / \mathrm{g})$ & $r^{2}$ \\
\hline $\mathrm{Ag}-\mathrm{CM}$ & 23.34 & 0.318 & 0.867 & 548.76 & 0.453 & 0.985 \\
\hline $\mathrm{CM}$ & 16.19 & 0.343 & 0.907 & 31.611 & 0.350 & 0.964 \\
\hline
\end{tabular}

desorption constant had similar values for both materials. It is unlikely that adsorption constant for the Ag-CM composite is $548.76 \mathrm{mg} / \mathrm{g}$ and $\mathrm{CM}$ has $31.61 \mathrm{mg} / \mathrm{g}$. It means that the composite is, effectively, a better material for the removal of MB from aqueous solution than the carbonaceous material. Nevertheless, correlation factor values were higher for both materials (over 0.9) than those founded with pseudo-first-order model. Then it can be elucidated that both materials may follow a chemical sorption of MB since carbonaceous material from sewage sludge and the composite with Ag NPs are highly heterogeneous materials. Figure $5 \mathrm{~b}$ shows the Elovich kinetic model fitting of the experimental adsorption of MB by $\mathrm{Ag}-\mathrm{CM}$ and $\mathrm{CM}$.

\section{Sorption isotherms}

Figure 6 shows the plots of equilibrium concentrations of MB dyestuff in the solid and liquid phases, which is $q_{\mathrm{e}}(\mathrm{mg} /$ $\mathrm{g})$ versus $C_{\mathrm{e}}(\mathrm{mg} / \mathrm{L})$ for $\mathrm{Ag}-\mathrm{CM}$ composite and $\mathrm{CM}$ using different amount of mass $(1 \mathrm{and} 10 \mathrm{mg}$ ). It can be noticed that when the solid material dosage increases, the removal of MB increases too. Moreover, there is no difference in this behaviour due to the sorbent material amount used.

Mathematical models were fitted to the experimental data when a mass of $1 \mathrm{mg}$ was used. It should be noted that the $\mathrm{CM}$ curves follow a common or normal behaviour, but the Ag-CM graphs do not exhibit a common behaviour of an isotherm. Then some constant values of each model will be out of context.

Different models have been developed for describing the behaviour of the materials fitting to different adsorption isotherms like linear model, Langmuir, Freundlich and Langmuir-Freundlich models in order to correlate the equilibrium adsorption data. $\mathrm{pH}$ data monitored before the experiment were $5.5 \pm 0.1$ for both materials, and after the experiment were 6.7 and 6.2 for $\mathrm{Ag}-\mathrm{CM}$ composite and $\mathrm{CM}$, respectively.

\section{Linear model}

When an isotherm behaves linearly, the pendant represents the distribution coefficient, $K_{\mathrm{d}}$ (Fall et al. 2001), which is defined as the relation between the amount of MB in the solid phase and the concentration of $\mathrm{MB}$ in the aqueous phase.

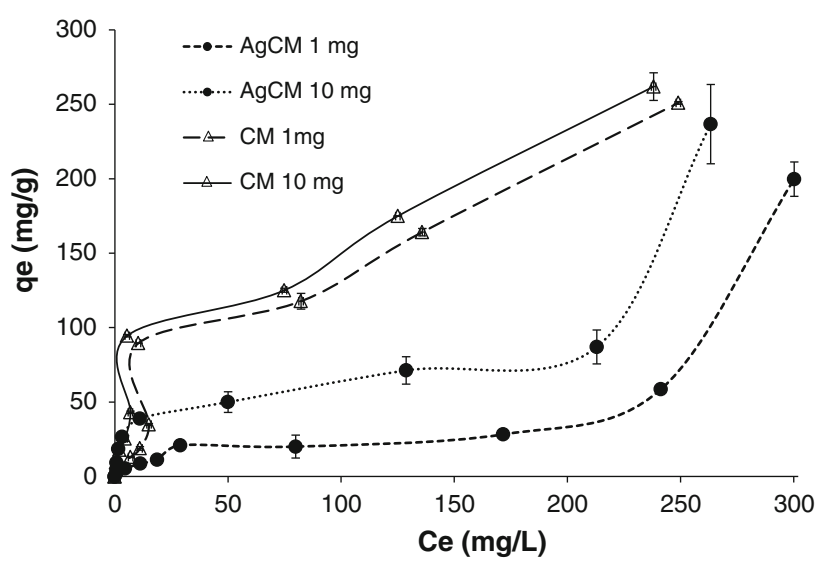

Fig. 6 Isotherm studies of Ag-CM composite and CM

A low value of $K_{\mathrm{d}}$ represents that the $\mathrm{MB}$ is in the solution, while a high value of $K_{\mathrm{d}}$ indicates that the dyestuff has affinity for the solid material (Alemayehu and Lennartz 2009). The linear isotherm is represented by the following equation:

$q_{\mathrm{e}}=K_{\mathrm{d}} C_{\mathrm{e}}$

where the sorption capacity is $q_{\mathrm{e}}(\mathrm{mg} / \mathrm{g}), K_{\mathrm{d}}$ is the distribution coefficient $(\mathrm{L} / \mathrm{g})$, and $C_{\mathrm{e}}$ is the amount and the concentration of $\mathrm{MB}$ at equilibrium $(\mathrm{mg} / \mathrm{L})$.

Figure 7a presents the linear model for adsorption of MB by Ag-CM composite and CM. It can be seen that the carbonaceous material had a higher pendant value $(0.981)$ compared with the value of 0.454 obtained for the $\mathrm{Ag}-\mathrm{CM}$ composite, which means that the $\mathrm{CM}$ has a better affinity for the dye molecule, but does not mean that removes it more.

Therefore, effective removal of the dyestuff by the two materials was performed. However, the materials do not follow the same removal mechanism. Carbonaceous material may remove the $\mathrm{MB}$ dye through a sorption mechanism, while the Ag-CM composite may remove MB by an oxidation-reduction reaction.

\section{Langmuir model}

Langmuir isotherm was theoretically derived supposing that the adsorption takes place on fixed homogeneous absorption sites of equal energy, forming a monolayer surface coverage. Langmuir model can be described by the following equation:

$q_{\mathrm{e}}=\frac{q_{0} b C_{\mathrm{e}}}{1+b C_{\mathrm{e}}}$

where $q_{0}$ is the maximum adsorption capacity of MB in the solid material, $C_{\mathrm{e}}$ is the liquid-phase equilibrium concentration of the dyestuff, $q_{\mathrm{e}}$ is the amount of MB dye adsorbed, and $b$ is the constant related to the energy or net enthalpy of adsorption. 
Fig. 7 a Linear model and b Langmuir-Freundlich model for adsorption of MB by Ag-CM composite and $\mathrm{CM}$
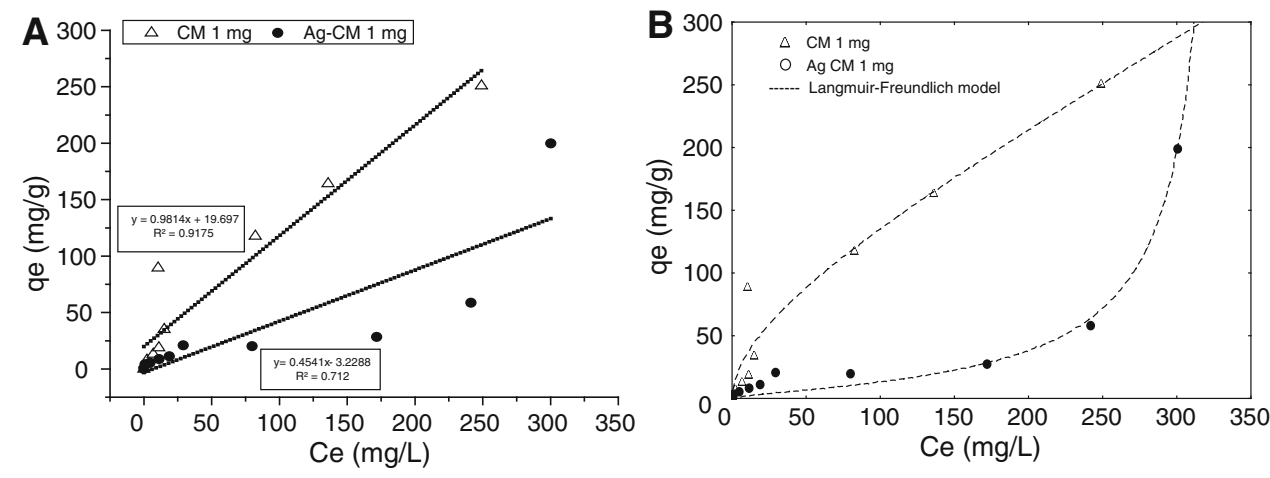

Table 3 Sorption isotherm parameters of MB by Ag-CM composite and CM

\begin{tabular}{|c|c|c|c|c|c|c|c|c|c|}
\hline \multirow{3}{*}{$\begin{array}{l}\text { Material } \\
(10 \mathrm{mg})\end{array}$} & \multicolumn{9}{|c|}{ Sorption isotherms } \\
\hline & \multicolumn{3}{|l|}{ Langmuir } & \multicolumn{3}{|l|}{ Freundlich } & \multicolumn{3}{|c|}{ Langmuir-Freundlich } \\
\hline & $q_{0}(\mathrm{mg} / \mathrm{g})$ & $b$ & $r^{2}$ & $K_{\mathrm{F}}(\mathrm{mg} / \mathrm{g})$ & $1 / n$ & $r^{2}$ & $K$ & $1 / n$ & $r^{2}$ \\
\hline Ag-CM & 11,787 & 0.00003 & 0.841 & 0.0012 & 3.401 & 0.966 & 0.471 & 0.574 & 0.991 \\
\hline $\mathrm{CM}$ & 418.03 & 0.0054 & 0.960 & 8.04 & 0.620 & 0.970 & 10.05 & 0.522 & 0.971 \\
\hline
\end{tabular}

Table 3 shows the isotherm parameters of $\mathrm{MB}$ treated with Ag-CM composite and CM. With this mathematical model the maximum adsorption capacity $\left(q_{0}\right)$ of any material can be known. So, this value was really lower for CM in comparison with the adsorption capacity value of the composite. Also, correlation coefficient values were good for both materials. Therefore, adding silver nanoparticles to the carbonaceous material makes the removal of $\mathrm{MB}$ more efficient. The Ag-CM composite has a very good capacity for the removal of the dyestuff from aqueous solution. According to Albuquerque et al. (2008), the typical kinetics of MB adsorption onto $\mathrm{SiO}_{2} / \mathrm{Bi}_{2} \mathrm{~S}_{3}$ surface can be considered as Langmuir type. Also, Al-Qodah et al. (2007) demonstrated that the adsorption of methylene blue by acid-treated diatomite is characterized by monolayer coverage of the adsorbate molecules on the adsorbent surface. Table 4 shows different materials used in the removal of methylene blue dye. It can be noticed that both materials used in this work have pretty good sorption capacities compared with those materials found in the literature according to Langmuir model.

\section{Freundlich model}

The Freundlich isotherm has the following form:

$q_{\mathrm{e}}=K_{\mathrm{F}} C_{\mathrm{e}}^{1 / n}$

where $q_{\mathrm{e}}$ is the amount of dye adsorbed, $C_{\mathrm{e}}$ is the equilibrium concentration of dye in solution, $K_{\mathrm{F}}$ can be taken as a relative indicator of adsorption capacity, and $1 / n$ is indicative of energy or intensity of the reaction.

The Freundlich and $n$ constants for both materials have very different values. It can be observed, in Table 3 , that the
Table 4 Comparison of sorption capacities by different adsorbent materials for methylene blue dye

\begin{tabular}{lll}
\hline Material & $\begin{array}{l}\text { Sorption capacity } \\
(\mathrm{mg} / \mathrm{g})\end{array}$ & Reference \\
\hline Rice husk & 312 & McKay et al. (1999) \\
Tea waste & 86.16 & Uddin et al. (2009) \\
Garlic peel & $82.64-142.86$ & Hameed et al. (2009) \\
$\begin{array}{l}\text { Spent tea leaves } \\
\text { Coconut bunch waste }\end{array}$ & 300.05 & Hameed (2009) \\
$\begin{array}{l}\text { Banana peel } \\
\text { Tanned solid wastes }\end{array}$ & 154.92 & Hameed et al. (2008) \\
Coconut husk activated & 434.78 & Annadurai et al. (2002) \\
carbon & & Tahiri et al. (2002) \\
Carbonaceous material & 418.03 & Tan et al. (2008) \\
from sewage sludge & & This work \\
Ag-CM composite & 11,787 & This work \\
\hline
\end{tabular}

Reference: Bhatnagar and Sillanpää (2010)

$\mathrm{CM}$ has a better adsorption capacity in comparison with the Ag-CM composite but experimentally it is the opposite. Also, the reciprocal of $n$ value is the adsorption intensity; if $1 / n<1$, the adsorption is favourable, but if $1 / n>1$, the adsorption is unfavourable (Slejko 1985). Then, the CM had a $1 / n$ value of 0.620 ; this indicates that adsorption intensity is favourable while the composite had a $1 / n$ value of 3.401 , which indicates that adsorption intensity is unfavourable. Correlation coefficient values were higher for two materials. However, it is important to notice that the mathematical models only help to elucidate the mechanism by which the two materials used perform the removal of MB. 
Fig. 8 Oxidation and reduction structural forms of methylene blue molecule<smiles>CN(C)C1=C[C-]2[Se]c3cc(N(C)C)ccc3N=C2C=C1</smiles><smiles>CN(C)c1ccc2c(c1)Sc1cc(N(C)C)ccc1N2</smiles>

\section{Langmuir-Freundlich model}

The Langmuir-Freundlich isotherm is a combination of the Langmuir and Freundlich models, indicating that the removal of MB is carried out by combined mechanisms on heterogeneous materials. This model is expressed by the following equation:

$q_{\mathrm{e}}=\frac{K C_{\mathrm{e}}^{1 / n}}{1+b C_{\mathrm{e}}^{1 / n}}$

where $q_{\mathrm{e}}$ is the amount of dye adsorbed in $\mathrm{mg} / \mathrm{g}, C_{\mathrm{e}}$ is the equilibrium concentration of dye in solution $(\mathrm{mg} / \mathrm{L}), K$ and $b$ are empirical constants of Langmuir model, and $1 / n$ is the Freundlich coefficient.

Table 3 shows the isotherm parameters of MB by the two materials. The Langmuir-Freundlich constant also had very different values for each material. The carbonaceous material showed the highest value of $q_{\mathrm{e}}$, which means that this material has a better sorption capacity than the Ag-CM composite. Nevertheless, the reciprocal values of the $n$ constant were similar, having 0.574 and 0.522 for $\mathrm{Ag}-\mathrm{CM}$ and $\mathrm{CM}$, respectively, which means that both materials exhibit a favourable adsorption (Slejko 1985). Correlation factor values were also higher for both materials to those found with Langmuir and Freundlich models; these values were over 0.9.

Figure $7 \mathrm{~b}$ shows the Langmuir-Freundlich isotherm model for the adsorption of MB by Ag-CM and CM using Statistics 6.0 software. Similar results were obtained by AlGhouti et al. (2003); the experimental data were fitted to the Langmuir and Freundlich equations to describe the adsorption of MB using diatomaceous earth.

Finally, Fig. 8 shows the chemical molecule of MB in the oxidation and reduction forms. It has been observed that some of the values obtained by fitting the Ag-CM experimental data to the isotherm models were not common because of the high sorption capacities and speed. Assuming that Ag NPs are placed as a catalyst on the surface and inside the pores of the carbonaceous material, the contact of Ag-CM composite with the $\mathrm{MB}$ in the aqueous solution may provoke the oxidation of silver and, at the same time, the reduction of the dye molecule producing the leucomethylene form.

\section{Conclusion}

Ag-CM nanocomposite has been successfully prepared with a novel, one-step green method, using $C$. sinensis aqueous extract as a reducing agent. This bioreduction method has proved to be uncomplicated, cost-effective and environmentally friendly to obtain nanostructured Ag-carbonaceous material composite, which exhibited very good performance for the removal of $\mathrm{MB}$ from aqueous solution than the $\mathrm{CM}$ alone. This new material can solve two problems: the disposal of sewage sludge and the removal of a dyestuff from water. Removal of $10 \mathrm{~mL}$ of aqueous solution of $\mathrm{MB}\left(C_{\mathrm{i}}=30 \mathrm{mg} /\right.$ L) using $10 \mathrm{mg}$ of the $\mathrm{CM}$ and $\mathrm{Ag}-\mathrm{CM}$ composite were 60 and $91 \%$ after 30 and $9 \mathrm{~h}$ of contact time, respectively. Experimental data were adjusted to different kinetic and isotherm models, where both materials fit the second-order and Langmuir-Freundlich models, respectively. Thus, both materials have heterogeneous surfaces; nevertheless, the removal of MB in the carbonaceous material seems to be occurring only by sorption, and in the Ag-CM composite, sorption and a redox reaction may be responsible for elimination of MB.

Acknowledgments Authors are grateful to UAEM for financial support. We also thank F. Ruiz, Eric Flores and I. Gradilla from CNyN-UNAM for technical support in TEM, BET and SEM/EDS, respectively.

\section{References}

Albuquerque R, Neves MC, Mendonca MH, Trindade T, Monteiro OC (2008) Adsorption and catalytic properties of $\mathrm{SiO}_{2} / \mathrm{Bi}_{2} \mathrm{~S}_{3}$ nanocomposites on the methylene blue photodecolorization process. Colloids Surf A Physicochem Eng Aspects 328:107-113

Alemayehu E, Lennartz B (2009) Virgin volcanic rocks: kinetics and equilibrium studies for the adsorption of cadmium from water. J Hazard Mater 169:395-401

Al-Ghouti MA, Khraisheh MAM, Allen SJ, Ahmad MN (2003) The removal of dyes from textile wastewater: a study of the physical characteristics and adsorption mechanisms of diatomaceous earth. J Environ Manage 69:229-238

Al-Qodah Z, Lafi WK, Al-Anber Z, Al-Shannag M, Harahsheh A (2007) Adsorption of methylene blue by acid and heat treated diatomaceous silica. Desalination 217:212-224

Anastas PT, Kirchhoff MM (2002) Origins, current status, and future challenges of green chemistry. Acc Chem Res 35:686-694

Annadurai G, Juang RS, Lee DJ (2002) Use of cellulose-based wastes for adsorption of dyes from aqueous solutions. J Hazard Mater 92:262-274

Bali R, Razak N, Lumb A, Harris AT (2006) The synthesis of metallic nanoparticles inside live Plants. Nanoscience and nanotechnology international conference (ICONN). IEEE Conference publications, pp 224-227. doi:10.1109/ICONN.2006.340592

Bhatnagar A, Sillanpää M (2010) Utilization of agro-industrial and municipal waste materials as potential adsorbents for water treatment-a review. Chem Eng J 157:277-296

Bhattacharya D, Gupta RK (2005) Nanotechnology and potential of microorganisms. Crit Rev Biotechnol 25:199-204 
Bokare AD, Chikate RC, Rode CV, Paknikar KM (2007) Effect of surface chemistry of $\mathrm{Fe}-\mathrm{Ni}$ nanoparticles on mechanistic pathways of azo dye degradation. Environ Sci Technol 41:7437-7443

Colín-Cruz A, López-Castañares R, Olea-Cardoso O, Barrera-Díaz C, Valdez-Flores C (2001) Products generated from the thermal treatment of sewage sludge. In: Specialised conference on sludge regulation, treatment, utilization and disposal. International water association (IWA)-UNAM-UAM, Acapulco, México, pp 164-171

Eustis S, Hsu HY, El-Sayed MA (2005) Excitation in colloidal solutions. A proposed molecular mechanism. J Phys Chem B 109(11):4811-4815

Fall C, Chavarie C, Chaouki J (2001) Generalized model of pentachlorophenol distribution in amended soil-water systems. Water Environ Res 73:110-117

Gericke M, Pinches A (2006) Biological synthesis of metal nanoparticles. Hydrometallurgy 83:132-140

Hameed BH (2009) Spent tea leaves: a new non-conventional and low-cost adsorbent for removal of basic dye from aqueous solutions. J Hazard Mater 161:753-759

Hameed BH, Ahmad AA (2009) Batch adsorption of methylene blue from aqueous solution by garlic peel, an agricultural waste biomass. J Hazard Mater 164:870-875

Hameed BH, Mahmoud DK, Ahmad AL (2008) Equilibrium modeling and kinetic studies on the adsorption of basic dye by a lowcost adsorbent: coconut (Cocos nucifera) bunch waste. J Hazard Mater 158:65-72

He S, Guo Z, Zhang Y, Zhang S, Wang J, Gu N (2007) Biosynthesis of gold nanoparticles using the bacteria Rhodopseudomonas capsulate. Mater Lett 61:3984-3987

Hsieh C, Teng H (2000) Influence of mesopore volume and adsorbate size on adsorption capacities of activated carbons in aqueous solutions. Carbon 38:863-869

Kargi F, Ozmihci S (2004a) Biosorption performance of powdered activated sludge for removal of different dyestuff. Ind Enzyme Microb Technol 35:267-271

Kargi F, Ozmihci S (2004b) Comparison of adsorption performances of powdered activated sludge and powdered activated carbon for removal or turquoise blue dyestuff. Ind Process Biochem 40:2539-2544

Kelly KL, Coronado E, Zhao LL, Schatz GC (2003) The optical properties of metal nanoparticles: the influence of size, shape, and dielectric environment. J Phys Chem B 107:668-677

Kumar V, Yadav SK (2008) Plant-mediated synthesis of silver and gold nanoparticles and their applications. J Chem Technol Biotechnol 84(2):151-157

Kunwar PS, Mohan D, Sinha S, Tondon GS, Gosh D (2003) Color removal from wastewater using low-cost activated carbon derived from agricultural waste material. Ind Eng Chem 42:1965-1976

Ma LM, Ding ZG, Gao TY, Zhou RF, Xu WY, Liu J (2004) Discoloration of methylene blue and wastewater from a plant by a $\mathrm{Fe} / \mathrm{Cu}$ bimetallic system. Chemosphere 55:1207-1212

Mafune F, Kohno J, Takeda Y, Kondow TJ (2002) Full physical preparation of size-selected gold nanoparticles in solution: laser ablation and laserinduced size control. J Phys Chem B 106(31):7575-7577

McKay G, Porter JF, Prasad GR (1999) The removal of dye colours from aqueous solutions by adsorption on low-cost materials. Water Air Soil Pollut 114:423-438

Mittal A, Mittal J, Kurup L (2006) Batch and bulk removal of hazardous dye, indigo carmine from wastewater through adsorption. J Hazard Mater B 137:591-602

Mohanpuria P, Rana NK, Yadav SK (2008) Biosynthesis of nanoparticles: technological concepts and future applications. J Nanopart Res 10:507-517

Noguez C (2007) Surface plasmons on metal nanoparticles: the influence of shape and physical environment. J Phys Chem C 111:3806-3819

Rodríguez-González V, Obregón-Alfaro S, Lozano-Sánchez LM, Lee SW (2012) Rapid microwave-assisted synthesis of one-dimensional silver- $\mathrm{H}_{2} \mathrm{Ti}_{3} \mathrm{O}_{7}$ nanotubes. J Mol Catal A Chem 353-354:163-170
Rodríguez-Sánchez L, Blanco MC, López-Quintela MA (2000) Electrochemical synthesis of silver nanoparticles. J Phys Chem B 104:9683-9688

Rozada F, Calvo LF, Garcia AI, Martín-Villacorta J, Otero M (2003) Dye adsorption by sewage sludge-based activated carbons in batch and fixed-bed systems. Bioresour Technol 87:221-230

Serpil O, Fikret K (2006) Utilization or powdered waste sludge (PWS) for removal of textile dyestuffs from wastewater by adsorption. Environ Manage 81:307-314

Slejko FL (1985) Adsorption technology: a step-by-step approach to process evaluation and application. Marcel Dekker, New York

Slokar YM, Le Marechal AM (1998) Methods of decoloration of textile wastewaters. Dyes Pigm 37:335-336

Smith KM, Fowler GD, Pullket S, Graham NJD (2009) Sewage sludge-based adsorbents: a review of their production, properties and use in water treatment applications. Water Res 43:2569-2594

Tahiri S, Azzi M, Messaoudi A, Albizane A, Bouhria M, Younssi SA, Mabrour J (2002) Removal of methylene blue from aqueous solutions by adsorption on tanned solid wastes. J Am Leather Chem Assoc 97:261-266

Tan IAW, Ahmad AL, Hameed BH (2008) Adsorption of basic dye on high-surface-area activated carbon prepared from coconut husk: equilibrium, kinetic and thermodynamic studies. J Hazard Mater 154:337-346

Treguer M, Cointet C, Remita H, Khatouri J, Mostafavi M, Amblard J, Belloni J (1998) Dose rate effects on radiolytic synthesis of goldsilver bimetallic clusters in solution. J Phys Chem B 102:4310-4321

Trujillo-Reyes J, Sánchez-Mendieta V, Colín-Cruz A, MoralesLuckie R (2010) Removal of Indigo Blue in aqueous solution using $\mathrm{Fe} / \mathrm{Cu}$ nanoparticles and $\mathrm{C} / \mathrm{Fe}-\mathrm{Cu}$ nanoalloy composites. Water Air Soil Pollut 207:307-317

Trujillo-Reyes J, Sánchez-Mendieta V, Solache-Ríos M, Colín-Cruz A (2012a) Removal of remazol yellow from aqueous solution using $\mathrm{Fe}-\mathrm{Cu}$ and $\mathrm{Fe}-\mathrm{Ni}$ nanoscale oxides and their carbonaceous composites. Environ Technol 33(5):545-554

Trujillo-Reyes J, Solache-Ríos M, Vilchis-Nestor A, Sánchez-Mendieta V, Colín-Cruz A (2012b) Fe-Ni nanostructures and C/Fe$\mathrm{Ni}$ composites as adsorbents for the removal of a textile dye from aqueous solution. Water Air Soil Pollut 223:1331-1341

Uddin MT, Islam MA, Mahmud S, Rukanuzzaman M (2009) Adsorptive removal of methylene blue by tea waste. J Hazard Mater 164:53-60

Vautier M, Guillard C, Herrmann JM (2001) Photocatalytic degradation of dyes in water: case study of indigo and of indigo carmine. Catalysis 201:46-59

Vilchis-Nestor AR, Sánchez-Mendieta V, Camacho-López MA, Gómez-Espinosa RM, Arenas-A J (2008) Solventless synthesis and optical properties of $\mathrm{Au}$ and $\mathrm{Ag}$ nanoparticles using Camellia sinensis extract. Mater Lett 62:3103-3105

Wang X, Zhu N, Yin B (2008) Preparation of sludge-based activated carbon and its application in dye wastewater treatment. J Hazard Mater 153:22-27

Wang X, Fan H, Ren P, Yu H, Li J (2012) A simple route to disperse silver nanoparticles on the surfaces of silica nanofibers with excellent photocatalytic properties. Mater Res Bull 47(7):1734-1739

Wu ZC, Zhang Y, Tao TX, Zhang L, Fong H (2010) Silver nanoparticles on amidoxime fibers for photo-catalytic degradation of organic dyes in waste water. Appl Surf Sci 257(3):1092-1097

Xie J, Lee JY, Wang DIC, Ting YP (2007) High-yield synthesis of complex gold nanostructures in a fungal system. J Phys Chem C 111:16858-16865

Yuh-Shan H (2006) Review of second-order models for adsorption systems. Hazard Mater B136:681-689

Zhang G, Wang DJ (2008) Fabrication of heterogeneous binary arrays of nanoparticles via colloidal lithography. J Am Chem Soc 130:5616-5617 